\title{
Carbon offsetting programs in North America: assessing the involvement of the hospitality and tourism industry
}

\author{
R. Dodds, T. Bessada, J. Garcia, A. McDougall \& N. Thiesen \\ Ryerson University, Canada
}

\begin{abstract}
With increasing concerns of the growing emissions of greenhouse gases on a global scale by government agencies, academics, non-governmental organizations (NGO's) and businesses, the carbon offsetting market around the world has evolved. During this worldwide evolution, however, North America has remained at a near standstill with regards to carbon offsetting. The compliance and voluntary offsetting market, often seen as a temporary solution to mitigating climate change, has faced criticism on the actual projects and the lack of standards in place. This in turn has produced a high level of consumer confusion regarding the credibility of carbon offsets and its overall impact on reducing greenhouse gas (GHG) emissions. This study determines the status of the voluntary carbon offset market in North America and the current level of the hospitality and tourism industry in mitigating its impact on climate change.

Keywords: carbon offsetting, climate change, climate change impacts, climate change mitigation strategies, tourism and climate change, emission trading.
\end{abstract}

\section{Introduction}

It is only in the last decade that the potential impacts of climate change on the global tourism industry have become a topic of discussion. Although there is a natural cycle of climate changes [2], the extreme changes that are now facing the planet are directly related to the rapid technological advances and population growth in the last century [2]. Many of the technologies and practices that have come to better humanity also cause these climatic changes through the release of greenhouse gases. 
The Intergovernmental Panel on Climate Change (IPCC) defines climate change as

"...a change in the state of the climate that can be identified (e.g. using statistical tests) by changes in the mean and/or the variability of its properties, and that persists for an extended period, typically decades or longer. Climate change may be due to natural internal processes or external forcings, or to persistent anthropogenic changes in the composition of the atmosphere or in land use." [3]

Literature on both tourism and climate change is increasing [4-7], but there remains little research within the North American context. According to Hamilton et al. [8], the literature on tourism and its relation to climate change "lacks an analysis of the global changes in tourism demand". Climate change's most severe impacts could result in sea-level rise, degradation of coral reefs, fire outbreaks, and an alteration in migrating patterns of birds and animals [9], which would considerably impact the appeal of various tourism destinations. The impacts of climate change on the tourism industry have been categorized into direct climatic impacts (e.g. redistribution of climatic assets among tourism regions), indirect environmental change impacts (e.g. water shortages, biodiversity loss), impacts of mitigation policies on tourist mobility (e.g. changes in tourism flows due to increased prices) and indirect societal changes (e.g. changes in economic growth) [10].

Arguably, if climate change is not properly addressed it could lead to a shift in the attractiveness of destinations around the world [9]. Mitigation strategies and the need for such adaptive measures acquire relevance as Gössling [11] suggests that $\mathrm{CO}_{2}$ emissions (adjusted for nitrous oxides and water emitted by aircrafts) from tourism may be in the order of $5.3 \%$ of the global total. These figures are attracting attention to the tourism sector as a considerable emitter of GHGs. Furthermore, while some locations could experience higher levels of attractiveness due to favourable temperatures, other destinations could become less appealing, thereby causing a shift in visitation patterns [12].

\section{Tourism impacts in North America}

Climatic observations in the last few decades point to seasonal variances which have impacted regions across North America. For example, Scott and Jones [13] indicate that on average, winters are 1.9 degrees Celsius warmer now than they were in the 1940s. They note that impacts from climate change could result in a reduction of ice cover on Canada's lakes, while glacier coverage in the southern Rocky Mountains is estimated to have decreased by $25 \%$ in the 20 th century. The impacts of climate change will be visible to the recreational and naturebased tourism industry in Canada as warm weather outdoor recreational activities such as summer festivals, camping, golfing and public beach access could experience benefits from the longer operating seasons [13]. Consequently, winter recreation activities may be negatively affected, which could result in a 
decline or elimination of sports such as skiing, snowmobiling, or tourism related events such as winter festivals [7, 13, 14].

\section{Carbon offsetting as a climate change mitigation strategy}

There are numerous mitigation technologies and practices currently available on the market identified by the IPCC from various sectors, however, mitigation strategies for addressing GHG emissions from tourism include: reducing energy use, improving energy efficiency, increasing the use of renewable or carbon neutral energy, and sequestering carbon dioxide through carbon sinks [10]. Though the aforementioned initiatives are contributing to the reduction of the carbon footprint of government, businesses and individuals; carbon offsetting has also been put forth as a strategy for mitigating climate change.

The World Bank [15] defines a carbon offset as:

A financial instrument representing a reduction in greenhouse gas emissions. Although there are six primary categories of greenhouse gases, carbon offsets are measured in metric tons of carbon dioxideequivalent $(\mathrm{CO} 2 \mathrm{e})$. One carbon offset represents the reduction of one metric ton of carbon dioxide, or its equivalent in other greenhouse gases.

In 2008, the volume of the global voluntary offset market on project based transactions was 54 metric tons $\mathrm{CO}_{2}$ equivalents $\left(\mathrm{MtCO}_{2} \mathrm{e}\right)$ and valued at $\$ 397$ million US [16]. The five main types of carbon offsetting projects sold are the following: renewable energy, energy efficiency, methane capture, industrial gases and biological sequestration [17, 18]. Providers of carbon offsets offer to 'neutralize' emissions caused by consumption in one sector (e.g. a flight) through compensation in another sector, such as investing in renewable energy, energy efficiency, or forestry projects [19]. The global concern on the level of GHG emissions and the impact of climate change has given rise to hundreds of carbon offsetting companies around the world. In North America, the voluntary carbon offsetting marketplace is comprised of both for profit and not-for profit companies. The main issues with regard to carbon offsetting include the types of projects and their location, lack of standards, permanence, leakage and additionality $[17,18,20]$.

There are five main issues when discussing offsetting. First, the types of projects are pertinent to determine the most efficient means in reducing emissions. Reforestation projects, included in biological sequestration, have been contested and criticized for their lack of permanence, leakage and lack of addressing the over-consumption and dependence on fossil fuels. Second, carbon offset providers generally follow their own standards for validation and verification, with a low degree of transparency [21]. The credibility and efficiency of offsetting schemes have been questioned and project-specific criticism has been made widely available to the public [22]. To ensure the credibility and efficiency of carbon offsetting programs, several standards have 
been established [18]. The highest voluntary standard in the world is the Gold Standard, which ensures that key environmental criteria have been met and are only be applicable to renewable energy/energy efficiency projects [23].

Third, permanence refers to the "durability of the climate benefits from an offset project, and varies depending on the offset project type" [24]. The issue of permanence is not addressed with projects such as biological sequestration, which includes tree planting or agricultural sequestration. In instances where trees are killed by fires, disease or logging, all the stored carbon will be released back into the atmosphere, therefore, cancelling the climate benefit of that offset project [24]. Until long-term monitoring can be effectively pursued, permanence in biological sequestration projects cannot be ensured. Fourth, leakage is another major issue with carbon offsetting projects as a reduction in GHG in one region may consequently cause an increase in emissions in another area [24]. This is most commonly seen in biological sequestration projects wherein projects that avoid deforestation preserve forests from conversion to other land uses. Carbon offset vendors need to anticipate leakage and minimize its effects during the project design stage and account for any leakage in total offset reduction calculations $[18,24]$.

Lastly, the concept of 'additionality,' meaning “...the project would not have happened without the extra funding from the sale of offsets" [20], must be considered as the quality of the offsets and the criteria for project selection needs to be effectively measured and reported to ensure credibility of the offsetting company [17].

\section{Carbon offsetting in tourism}

Many companies realize the importance of adapting carbon mitigation strategies and have begun to implement carbon offsetting programmes directed toward their consumers. Voluntary schemes give airline passengers the option to pay extra to have a carbon neutral flight [25]. While compulsory carbon offsets ensure that all air travellers pay a levy, which is then used for approved offset programs.

Some offsetting companies are beginning to understand the high levels of confusion that consumers have surrounding the carbon-offsetting concept [26]. As a result, they provide individual consumers with the option to calculate their emissions in terms of flight distance, which produces a breakdown by price and offsetting project. This indicates the fact that consumers need, and want, to know where and how their carbon purchase will be used. It is also difficult for consumers to distinguish between the various forms of carbon credits, such as Emission Unit Allowance (EUAs), and Gold Standard Verified Emission Reductions (GS VERs) [21]. One question being asked by many is whether voluntary carbon offsets can play a significant role in mitigating the contribution of aviation to climate change [27]. Although these schemes have grown in recent years, the overall amount of emissions offset remains negligible in that tour operators and airlines report that customers show limited interest [21]. 


\section{Methodology}

The purpose of this study was to determine the status of the voluntary carbon offsetting market in North America and the current level of involvement of the hospitality and tourism industry in mitigating its impact on climate change. A list of 50 carbon offsetting companies in North America (Canada and USA) was compiled and a total of 20 respondents participated in the study (40\% response rate). Telephone interviews were used to collect the data, along with three email questionnaires which were sent to those respondents unable to participate in the phone interview. The data collection process took place in October, 2009.

The specific objectives of this study were to:

Obtain information from North American carbon offsetting companies about the current buy-in from hospitality and tourism companies

Obtain information about the companies' offsetting standards and project types offered

Assess current issues or confusion related to offsetting

A qualitative interviewing system was chosen due to the importance of having a dialogue between the researcher and the interviewee. This system was important to the research process as it enabled the researcher and the interviewee to produce in-depth information based on interviewees' insights [28]. A semistructured interview was used to allow for adaptability of the interviewer, comprised of both open and closed questions and was designed to be approximately 30 minutes in length. Several carbon offsetting reports were used to assist in formulating the questions, while a cluster analysis and coding of the interview information was used to analyze the data.

\section{Findings}

Carbon offsetting companies in North America have been in business for an average of five years. $31 \%$ of total carbon offsetting revenue is produced by individual consumers, while $69 \%$ is from corporate business, which includes Small and Medium Enterprises (SMEs). The average number of tonnes of $\mathrm{CO}_{2}$ offset in the 2008 fiscal year was 163,914 tonnes and $57 \%$ of projects were located within North America.

Respondents were asked to identify which industry is their biggest client in purchasing carbon offsets. 33\% of respondents identified hospitality and tourism companies as their most prominent industry, followed by the service sector at $26.67 \%$, which excludes hospitality and tourism clients. Respondents were then asked to state the projects available to their clients, which were classified into five major categories. $65 \%$ of respondents offer renewable energy and biological sequestration projects, which were also identified by $50 \%$ of respondents as the most popular carbon offset purchased

The study found that the hospitality and tourism industry was the leading industry using offset providers, representing approximately $19 \%$ of all offset 
business. It was found that the most prominent sector within the hospitality and tourism industry is festivals and events, accounting for $5 \%$ of the total customer base. $80 \%$ of respondents agreed that barriers to purchasing offsets exist, of which $40 \%$ identified cost and lack of education as major barriers. The other barriers disclosed were legitimacy of carbon offsets $(10 \%)$, negative consumer perception $(5 \%)$, transparency $(10 \%)$, lack of communication $(15 \%)$ and lack of government regulation $(5 \%)$. One respondent noted that it is imperative that offsetting companies "make clear and accurate statements as to what they are doing and how they are doing it", while also meeting third party standards.

Based on two respondents' opinions, the intangibility of tourism products and scepticism associated with carbon offsetting further contributes to the barriers to buy-in for the hospitality and tourism industry. As one respondent commented, the complexity of carbon offsetting in the hospitality and tourism industry is made evident as it "is simpler to do for travel," meaning that a precise number can be calculated based on miles travelled. However, when it comes to the festivals and events sector, the "calculations are complicated, especially for those who go to the event, as there are complications of calculating the total footprint" as noted by one respondent.

Respondents were asked what recognized standards have been adopted to certify their carbon offsets. $90 \%$ of North American carbon offsetting companies surveyed said they were certified by a particular standard. No information was provided as to the number of projects certified by each standard. It was determined that 14 different certifications and standards were used by the North American carbon offsetting companies interviewed; the most predominant being Voluntary Carbon Standard (33\%), ISO Certification (28\%), the Climate, Community and Biodiversity Alliance (28\%) and the Gold Standard (22\%). 67\% of respondents stated that standards were the best way to ensure that carbon offsets are additional. 84\% of respondents answered that $100 \%$ of their offsets are validated and verified by accredited third parties. In addition, 63\% of respondents stated that third party verification was a method used to ensure that carbon offsets were quantified accurately.

When respondents were asked how carbon offsetting companies could reduce the level of confusion in the marketplace, the majority said adhering to standards was the best method at $45 \%$, followed closely by education and transparency, each at $40 \%$. When respondents were asked how they educate their clientele about climate change, $70 \%$ of respondents stated that blogs and website information was a method used to educate their buyers. Education of the general public is an important element of carbon offsetting. As one respondent states, "selling offsets is only half of our business; the other half is educating our clients and people on understanding climate change and how to reduce their impact."

\section{Discussion}

Based on the findings of this research, several major themes emerged: involvement of the hospitality and tourism industry, financial commitment, 
confusion in the marketplace, transparency and lack of education, which was consistent with the reviewed literature [18, 22].

According to Bows et al. [6], given the importance of tourism and its contribution to global greenhouse emissions, action in mitigating impacts is necessary. It is important to note that based on the research findings and literature reviewed, festivals and events represent the most active hospitality and tourism sector in purchasing offsets [29], while the least active is the cruise sector [30]. 50\% of respondents agreed that there is a lack of understanding regarding climate change in the hospitality and tourism industry, which indicates the need for climate change education in this sector. $40 \%$ of respondents indicated that cost is a major barrier to buy-in for the hospitality and tourism industry, which was not revealed in the literature. Since the industry is made up of mainly SMEs, the additional cost of purchasing carbon offsets would be a logical barrier to buy-in.

Confusion in the marketplace was a reoccurring theme throughout the findings of this research. $85 \%$ of respondents agreed that confusion exists within the marketplace. The lack of education, need for regulation, number of standards, and transparency all relate to the issue of confusion in the marketplace. According to Dodds et al. [26], Canadian carbon offsetting companies are beginning to understand the amount of confusion consumers are facing related to carbon offsetting. In addition, the sheer number of available standards and varying criteria is contributing to confusion. Among all respondents certified by a standard, 14 different standards were identified. By working with offsetting companies to ensure that standards are globally accepted, confusion could be reduced though proper explanation of standards to the general public. The offset market will continue contributing to consumer confusion until it develops comprehensive quality standards, concrete auditing processes, and effective disclosure.

Carbon offsetting is a relatively new industry, as this research showed respondents have been in operation on average for five years. This explains the confusion of consumers in their attempt to find a reliable supplier and lack of adherence to a unified standard regulating the industry. It is therefore possible that many hospitality and tourism companies would be hesitant to allocate scarce financial resources to those companies with little credibility. As Gössling et al. [22] suggests, confusion is related to the role that credibility, education and communication play in the carbon offsetting scheme which is consistent with this research.

It is assumed that many hospitality and tourism companies are basing their decisions on buying-in to carbon offsets on reports published by NGOs or government bodies. As identified by one respondent, this information is not necessarily the most objective in terms of both project choices and companies reviewed. In addition, there are few reports available within North America in relation to carbon offsetting, and none which pertain the hospitality and tourism industry. Consequently there is little documentation to aid this sector in making an informed decision related to carbon offsetting for the hospitality and tourism industry. 
When asked how carbon offsetting companies could reduce the level of confusion in the marketplace, $40 \%$ percent of respondents stated transparency. This finding is consistent with the literature in that there is much confusion in the marketplace [21,26]. The topic of transparency also ties into the need for government regulation, because once rules have been put in place, companies abide by them or have to close their business.

Education has a critical role to play in disseminating confusion and addressing the various issues associated with carbon offsetting. Ultimately, the need for education on climate change and carbon offsetting could be a determining factor in the success of the carbon offsetting market. The lack of education is a concurrent issue with carbon offsetting, as mentioned by $40 \%$ of respondents. Currently, few carbon offsetting companies have become aware of incorporating elements of consumer education into their business strategies. Lack of education also extends to companies offering carbon offsets as they continue to sell projects that are highly contentious. For example, biological sequestration is not Gold Standard Certified and is highly scrutinized on the basis of permanence risk [24]. This contributes to further confusion as there is an absence of knowledge about projects within the industry and the general public. While some proactive educational strategies, such as educational webinars, publications, and carbon calculators demonstrate the interest of carbon offsetting companies in educating the consumer, there is often a reliance on the pre-determined understanding of the issues.

\section{Recommendations and conclusions}

A number of recommendations, in relation to minimizing the overall level of confusion within the North American carbon offsetting market can be suggested to help move this industry forward.

In order to improve the carbon offsetting market and reduce confusion, an international government framework must be established. This global framework would create an internationally recognized standard for all carbon offsetting companies. Government participation needs to be pursued in order to address the issues associated with carbon offsetting. Some carbon offsetting companies are already educating their clients on how to offset their emissions, however there needs to be a comprehensive educational component on climate change and carbon offsetting as a mitigation tool. If carbon offsetting companies implement better educational strategies, it may attract more clientele from the hospitality and tourism sector.

Additional research needs to be undertaken regarding the opinions of companies and consumers within the hospitality and tourism industry. There would be value in replicating this study in the future to determine the progress of the hospitality and tourism industry and if the barriers have been addressed.

As the tourism industry is a major contributor of GHG emissions, hospitality and tourism companies need to take responsibility for their impacts, and begin to reduce their footprint. Overall, the hospitality and tourism industry accounts for $19 \%$ of total offsets purchased, with the festival and events sector purchasing the 
majority of offsets. This research also revealed that cost and lack of education were the most prominent barriers to buy-in from hospitality and tourism companies in North America, while biological sequestration and renewable energy were identified as the most common types of projects offered. Moreover, it was identified that adhering to standards and further education was the most commonly mentioned method of reducing confusion in the market place by respondents. Five major themes emerged from this research including the current involvement of the hospitality and tourism industry, its financial commitment, the confusion in the marketplace, the lack of education and transparency. Recommendations from this study include the need for regulation of the voluntary carbon offset market and government action in establishing an international regulatory body to standardize offset projects. Further education is required for carbon offsetting companies, the hospitality and tourism industry and the end consumer on their understanding of climate change, its impacts and the utilization of carbon offsets as a mitigation strategy.

\section{Limitations}

The geographic spread of companies across North America and varying time zones hindered the availability of companies to complete the phone interviews.

Due to the controversy associated with carbon offsetting, there was some hesitation in disclosing financial and company information.

Carbon offsetting companies that had no hospitality and tourism industry clients might have been deterred from participating in this study, moreover several companies felt ineligible to participate based on their recent entry into the carbon offsetting market.

The rapid growth of the voluntary carbon offsetting market and the numerous sources referenced to compile the list of carbon offsetting companies may not be inclusive of all current operating carbon offsetting companies.

Many carbon offsetting companies have been prone to failure as demonstrated by the closure or the amalgamation of 13 companies within the length of the study, providing a decrease in the population sample of this research.

\section{References}

[1] McCright, A. and Dunlap, R. (2003). Defeating Kyoto: The conservative movement's impact on U.S. climate change policy. Social Problems, 50(3), 348-373.

[2] IPCC (2007). Climate change 2007: Mitigation of climate change. Contribution of Working Group III to the Fourth Assessment Report of the Intergovernmental Panel on Climate Change, Bosch, P., Dave, R., Davidson, O., Metz, B., and Meyer, L. (eds), Cambridge University Press, UK.

[3] IPCC (2009). Annex 1: Glossary. Retrieved September 16, 2009 from Intergovernmental Panel on Climate Change: http://www.ipcc.ch/pdf/glossary/ar4-wg3.pdf 
[4] Becken, S. and Hay, J.E. (2007). Tourism and climate change: Risks and opportunities. Buffalo, N.Y.: Channel View Publications.

[5] Hall, C.M., and Higham, J.(Eds.) (2005). Aspects of Tourism: Tourism, recreation \& climate change. Clevedon: Channel View Publications.

[6] Bows, A., Anderson, K., and Peeters, P. (2009). Air transport, climate change and tourism. Tourism \& Hospitality: Planning \& Development, 6 (1), 7-20.

[7] Dodds, R., and Graci, S. (2009). Canada's tourism Industry-Mitigating the effects of climate change: A lot of concern but little action. Tourism \& Hospitality: Planning \& Development, 6 (1), 39-51.

[8] Hamilton, J.M., Maddison, and D., Tol, R.S.J. (2004) Climate change and international tourism: A simulation study. Global Environmental Change, 15 (3), 253-266.

[9] Agnew, M. D., and Viner, D. (2001). Potential impacts of climate change on International tourism. Tourism and Hospitality Research, 3 (1), 37.

[10] UNWTO \& UNEP. (2008). Climate Change and Tourism: Responding to global challenges. In United National Environment Programme (Ed), Madrid: World Tourism Organization, Paris: United National Environmental Programme.

[11] Gössling, S. 2002. Global environmental consequences of tourism. Global Environmental Change, 12 (4), 283-302.

[12] Amelung, B., Nicholls, S., and Viner, D. (2007). Implications of global climate change for tourism flows and seasonality. Journal of Travel Research, 45 (3), 285-296.

[13] Scott, D. and Jones, B. (2006b). Climate change \& seasonality: In Canadian outdoor recreation and tourism. Waterloo, ON: University of Waterloo, Department of Geography.

[14] Agrawal, S. (2007). Climate change in the European Alps: Adapting winter tourism and natural hazards management. Paris, France: OECD.

[15] World Bank (2008). Environmental sustainability: An evaluation of World Bank Group support. Washington: IEG publication.

[16] Capoor, K., and Ambrosi, P. (2009). The state \& trends of the carbon market. The World Bank. Retrieved September 17, 2009 from http://siteresources.worldbank.org/EXTCARBONFINANCE/Resources/Sta te and_Trends_of the_Carbon_Market_2009-FINALb.pdf

[17] Clean Air Cool Planet (2006). A Consumer's Guide to Retail Offset Providers. Portland. Clean Air Cool Planet.

[18] Kollmuss, A., Zink, H., and Polycarp, C. (2008, March). Making sense of the voluntary carbon market: A comparison of carbon offset standards. WWF Germany, Stockholm Environment Institute and Tricorona.

[19] Eisenkopf, A., and Knorr A. (n.d). Voluntary carbon offsets in the airline industry: A critical assessment. Retrieved October 1, 2009 from http://www.garsonline.de/Downloads/071128/Knorr\%20_Eisenkopf_Volun tary_Carbon_Offsets_Paper.pdf 
[20] David Suzuki Foundation (2009). What is a carbon offset? Retrieved September16, 2009 from http://www.davidsuzuki.org/ Climate_Change/What_You_Can_Do/carbon_offsets.asp

[21] Gössling, S., Haglund, L., Kallgren, H., Revahl, M., and Hultman, J. (2009). Swedish air travellers and voluntary carbon offsets: towards the cocreation of environmental value? Current Issues in Tourism, 12 (1).

[22] Gössling, S., Broderick, J., Upham, P., Peeters, P., Strasdas, W., Ceron, J.P., et al. (2007). Voluntary carbon offsetting schemes for aviation: Efficiency and credibility. Journal of Sustainable Tourism, 15 (3), 223248.

[23] Hamilton, K., Sjardin, M., and Marcello, T. (2009). Fortifying the foundation: State of the voluntary carbon markets 2009. Ecosystem Marketplace and New Carbon Finance. Retrieved October 5, 2009 from http://ecosystemmarketplace.com/documents/cms_documents/StateOfTheV oluntaryCarbonMarkets_2009.pdf

[24] Carlson, D., Lingl, P., Wong, R. (2009, July). Purchasing carbon offsets: A guide for Canadian consumer, businesses and organizations. David Suzuki Foundation, Pembina Institute.

[25] Dwyer, L. and Forsyth, P. (2008). Climate change policies, long haul air travel and tourism. Proceedings of the CAUTHE 2008 Conference (pp. 3). Australia: Griffith Education.

[26] Dodds, R., Smith, W., and Leung, M. (2008). Assessing awareness of carbon offsetting and travel agents. An International Journal of Tourism and Hospitality Research, 19 (1).

[27] Gössling, S., and Hall, C.M. (2008). Swedish tourism and climate change mitigation: An emerging conflict? Scandinavian Journal of Hospitality and Tourism, 8 (2), 141-158.

[28] Neuman, W.L. and Robson, K. (2009) Basics of Social Research: Qualitative and Quantitative Approaches. Pearson, Toronto.

[29] Econeutral. (2008). Clients. Retrieved October 30, 2009 from http://www.econeutral.com/clients.html

[30] Klien, R. A. (2011). Responsible cruise tourism: Issues of cruise tourism and sustainability. Journal of Hospitality and Tourism Management, (18), 107-116. 